\title{
Éric Méchoulan, La culture de la mémoire ou comment se débarrasser du passé?
}

Gabriella Bosco

\section{(2) OpenEdition}

1 Journals

\section{Edizione digitale}

URL: http://journals.openedition.org/studifrancesi/8427

DOI: 10.4000/studifrancesi.8427

ISSN: 2421-5856

\section{Editore}

Rosenberg \& Sellier

\section{Edizione cartacea}

Data di pubblicazione: 1 mai 2009

Paginazione: 226

ISSN: 0039-2944

\section{Notizia bibliografica digitale}

Gabriella Bosco, «Éric Méchoulan, La culture de la mémoire ou comment se débarrasser du passé?», Studi Francesi [Online], 157 (LIII | I) | 2009, online dal 30 novembre 2015, consultato il 09 janvier 2021. URL: http://journals.openedition.org/studifrancesi/8427 ; DOI: https://doi.org/10.4000/studifrancesi.8427

Questo documento è stato generato automaticamente il 9 janvier 2021.

\section{(c) $(7)$}

Studi Francesi è distribuita con Licenza Creative Commons Attribuzione - Non commerciale - Non opere derivate 4.0 Internazionale. 


\title{
Éric Méchoulan, La culture de la mémoire ou comment se débarrasser du passé?
}

\author{
Gabriella Bosco
}

\section{NOTIZIA}

ÉRIC MÉCHOULAN, La culture de la mémoire ou comment se débarrasser du passé?, Québec, Les Presses de l'Université de Montréal, 2007, pp. 261.

1 Il saggio di Éric méchoulan offre una riflessione sulla memoria intesa come imperativo categorico nelle società contemporanee. Commemorare la liberazione di Auschwitz e la data d'invenzione della minestra Campbell sembrano oggi due gesti fondamentalmente analoghi: che cosa ha portato a questo appiattimento del giudizio, a una tale ossessione delle tracce di ciò che è scomparso? L'A. individua il problema rappresentato dall'angoscia memoriale, che abolendo le distinzioni minaccia di generare un'amnesia generalizzata per sovrabbondanza di ricordi. Questo fenomeno epocale sarebbe, nella sua lettura, un tentativo di dimenticare i disastri del presente nella rassicurante salvaguardia del passato vista come un valore in sé. La modernità, scrive Éric Méchoulan, si è costruita su una necessaria rottura con il passato. La postmodernità, viceversa, ha trovato nella cultura del ricordo, nella trasformazione del tempo in memoria, il suo baluardo. In un movimento cioè che, livellando sullo stesso piano tutto ciò che è stato, ne relativizza il rapporto con ciò che è presente.

2 L'approccio al problema da parte di Méchoulan è come si vede filosofico e comporta necessariamente un risvolto: la riflessione sull'altra faccia della memoria, rappresentata dall'oblio.

3 Il tentativo proposto è quello di andare a cercare in una serie di testi delle "failles utiles", che - illustrando casi esemplari di cristallizzazione della memoria - permettano di far luce sulle ragioni del fenomeno. La prima parte del volume («La condition 
moderne de la mémoire», pp. 45-139) ha un andamento cronologico: parte da Nerval, il cui caso permette di cogliere simultaneamente la presenza fantomatica della memoria e le nuove poste in gioco dell'eredità del passato, e prosegue illustrando il processo di valorizzazione della memoria del presente nella modernità messo in luce da Baudelaire, attraverso esempi diversi quali Bergson, Nietzsche e Freud e il loro modo di dire i fatti. È poi indagando lo sguardo critico che porta su questa figura della memoria Walter Benjamin. E la dimensione ideologica del movimento di trasformazione della memoria da fatto in monumento viene illustrato tramite l'esempio del Partenone di Nashville. Mentre la problematicità di questa trasformazione è esemplificata a partire dai casi di Georges Perec e Janet Cardiff.

4 La seconda parte del volume («Le travail du passé», pp. 143-229) studia invece alcune costruzioni teoriche o letterarie - quelle di Paul Zumthor, Fernand Dumont, Guy Debord e Jacques Ferron - che rivelano in misura varia quanto l'ossessione memoriale sia in esse determinante, indipendentemente dalla volontà espressa da parte dei loro autori di riflettere sulla questione. È anzi spesso là dove il tema del rapporto con il passato sembra essere marginale, scrive l'A., che esso si fa più significativo.

5 La densa conclusione, intitolata «La mémoire obsolète» (pp. 231-251), propone una chiave interpretativa del fenomeno analizzato - il ricordo non del fatto ma della sua immagine - invitando a una lettura non catastrofista di esso, bensì per lo meno a doppia valenza: certamente positivo, ritiene l'A., è l'avvento correlato del concetto di tempo non lineare. «L'obsolescence est ainsi ce qui nous permet d'utiliser à nouveau ces instances comme des opérations ouvertement anachroniques», riassume Méchoulan usando le parole di David Gross: noi viviamo non in tempi uniformi e perfettamente chiusi su se stessi, conformi a visioni omogenee del mondo, bensì esistiamo in serie di sfasamenti immediati di cui la storia deve tener conto facendo posto alle "félures de l'Autrefois". In modo che il discorso della memoria apra il tempo degli uomini al futuro anteriore: a ciò che essi vi avrebbero potuto fare. 